\title{
CRESCIMENTO INICIAL DE SEIS ESPÉCIES FLORESTAIS EM DIFERENTES ESPAÇAMENTOS
}

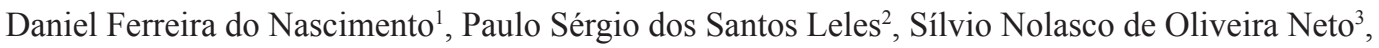 \\ Rodrigo Teixeira Soares Moreira ${ }^{4}$, Jorge Makhlouta Alonso ${ }^{5}$
}

(recebido: 22 de junho de 2010; aceito: 25 de novembro de 2011)

RESUMO: O objetivo deste trabalho foi verificar a influência do espaçamento de plantio no crescimento de seis espécies florestais, aos 22 meses de idade, em plantios de recomposição florestal, na Bacia do Rio Guandu. O experimento foi instalado na SFE Usina Termelétrica Barbosa Lima Sobrinho, Município de Seropédica-RJ. Foram utilizadas 48 espécies arbóreas, estabelecidas nos espaçamentos $1,0 \times 1,0 ; 1,5 \times 1,5 ; 2,0 \times 2,0$ e 3,0 x 2,0 m, os quais constituem os tratamentos. Aos 22 meses após plantio, avaliou-se o crescimento em altura, diâmetro ao nível do solo (DNS) e largura da copa para as espécies Anadenanthera macrocarpa Benth. Brenan (angico vermelho), Schinus terebinthifolius Raddi (aroeira pimenteira), Schizolobium parahyba Blake (guapuruvu), Chorisia speciosa St. Hill (paineira), Cordia sp. (babosa branca) e Inga marginata (ingá). Foi constatado que o crescimento das espécies comportou de maneira diferenciada nos espaçamentos de plantio, sendo que os mesmos influenciaram significativamente no crescimento inicial de todas as espécies. Concluiu-se que, de modo geral, nos espaçamentos mais amplos, as plantas apresentaram maior crescimento.

Palavras-chave: Recomposição florestal, plantio, reflorestamento.

\section{INITIAL GROWTH OF SIX FOREST TREE SPECIES IN DIFFERENTS SPACING CONDITIONS}

ABSTRACT: This work veriflied the influence of planting spacing on the initial growth of six forest species, at the age of 22 months, in plantations of forest recomposition in the Guandu River Basin. The experiment was installed in the SFE - thermoelectric power plants Barbosa Lima Sobrinho, located in the City of Seropédica-RJ. Forty eight tree species were planted, using the spacings, 1.0 $\times 1.0,1.5 \times 1.5,2.0$ and $2.0 \times 3.0 \times 2.0$ m, which are the study treatments. At 22 months after planting, it was evaluated the growth in height, diameter at ground level (DNS) and area of the canopy for the species, Anadenanthera macrocarpa Benth. Brenan (angico vermelho), Schinus terebinthifolius Raddi (aroeira pimenteira), Schizolobium parahyba Blake (guapuruvu) Chorisia speciosa St. Hill (paineira), Cordia sp. (babosa branca) and Inga marginata (ingá). It was found that the studied species behaved in a different way in the differents spacing of planting, and that the planting density significantly influenced on the initial growth of all the species. In general, in wider planting spacings, the plants had higher growth.

Key words: Forest restoration, planting, reforestation.

\section{INTRODUÇÃO}

Em função da crescente conscientização sobre a importância da preservação ambiental e do avanço das leis que disciplinam a ação humana sobre as florestas de proteção, nos últimos anos tem aumentado o incentivo para o plantio de espécies florestais nativas para a recomposição florestal. Exemplo desse incentivo é a Lei da Mata Atlântica (Lei no ${ }^{\circ} 11.428$ de 26/12/06), que no Art.36 menciona a criação do Fundo de Restauração do Bioma Mata Atlântica para projetos de restauração ambiental e de pesquisa científica. Nessa mesma lei, no Art. 39, estão previstos incentivos fiscais para o proprietário que tenha vegetação primária ou secundária em regeneração (BRASIL, 2006). Este e outros incentivos têm criado demanda para geração de conhecimento técnico-científico e o repasse dessas informações a sociedade.

Os estudos sobre as espécies florestais utilizadas em recomposição florestal, de uma maneira geral, são incipientes e relacionam-se, principalmente, às características botânicas e dendrológicas. Pouco se sabe sobre as características silviculturais, o padrão de crescimento e as exigências nutricionais das espécies nativas da flora brasileira. A implantação ou recomposição

\footnotetext{
${ }^{1}$ Engenheiro Florestal - Desenvix S/A. - Rua Prof. Aloisio Amâncio, 17, Bairro Bem Ti Vi - 28660-000 - Bom Jardim, RJ - daniel.nascimento@ desenvix.com.br

${ }^{2}$ Engenheiro Florestal, Professor Doutor em Produção Vegetal - Instituto de Florestas - Universidade Federal Rural do Rio de Janeiro/UFRRJ BR 465, km 7 -23890-000 - Seropédica, RJ - pleles@ufrrj.br

${ }^{3}$ Engenheiro Florestal, Professor Doutor em Ciência Florestal - Departamento de Engenharia Florestal - Universidade Federal de Viçosa/UFV 36571-000 - Viçosa, MG - snolasco@ufv.br

${ }^{4}$ Engenheiro Florestal - Instituto Estadual de Florestas - Rua Narciso Júnior, 480-36400-000 - Conselheiro Lafaiete, MG-rodrigosmoreira@yahoo.com.br ${ }^{5}$ Engenheiro Florestal, Mestrando em Ciências Ambientais e Florestais - Instituto de Florestas - Universidade Federal Rural do Rio de Janeiro/UFRRJ BR 465, km 7 - 23890-000 - Seropédica, RJ-j_makh@hotmail.com
}

Cerne, Lavras, v. 18, n. 1, p. 159-165, jan./mar. 2012 
de uma floresta requer o emprego de técnicas adequadas que serão definidas em função de uma avaliação detalhada das condições do local. Segundo Botelho (1998), dessa avaliação depende a seleção de espécies, técnicas de plantio, como definição do espaçamento, métodos de preparo do solo, adubação e manejo da vegetação.

Um fator de grande importância em programas de recomposição florestal é o espaçamento de plantio, o qual influencia na otimização do uso dos recursos disponíveis (REIS; REIS, 1993) na taxa de crescimento, no valor e na qualidade da matéria-prima, no recobrimento do solo e no manejo do povoamento, além dos custos de implantação e de manutenção (PIÑA-RODRIGUES et al., 1997b).

São inúmeros os estudos sobre espaçamentos de plantio para espécies tradicionais na silvicultura econômica, como as dos gêneros Pinus e Eucalyptus. Para as espécies nativas com potencial de cultivo alguns estudos sobre espaçamento foram conduzidos (FONSECA et al., 1990; NOGUEIRA; SIQUEIRA, 1977; RONDON, 2002; SOUZA, 2004), entretanto poucos são aqueles para reflorestamento com espécies nativas, com fins de recomposição da vegetação florestal, com povoamentos mistos.

Neste trabalho, objetivou-se verificar a influência do espaçamento de plantio no crescimento de seis espécies florestais nativas da flora brasileira, aos 22 meses de idade, em plantios de recomposição florestal.

\section{MATERIAL E MÉTODOS}

O experimento foi instalado, com o plantio das mudas, em novembro de 2004, em área pertencente à Sociedade Fluminense de Energia - Usina Termelétrica Barbosa Lima Sobrinho, atualmente pertencente à Petrobras, localizada no Km 200 da Rodovia Presidente Dutra, próxima ao Rio Guandu, no Município de Seropédica-RJ, Região da Baixada Fluminense. De acordo com dados de 2001 até 2005 , da estação metereológica, situada na própria UTE, a temperatura média máxima anual do local é de $29,3^{\circ} \mathrm{C}$, sendo a média mínima de $20,4^{\circ} \mathrm{C}$ e a temperatura média anual de $24,5^{\circ} \mathrm{C}$. A precipitação média é de $1.326 \mathrm{~mm}$ anuais, com maior concentração de chuvas no período de outubro a março, e baixa incidência em julho e agosto. O clima da região, segundo a classificação de Köppen, é do tipo Aw (BRASIL, 1980). A área apresenta topografia plana e com predomínio de Panicum maximum (capim colonião). A análise química do solo revelou os seguintes valores: $\mathrm{pH}($ em água $)=5,1 ; \mathrm{P}$ e $\mathrm{K}=5$ e $130 \mathrm{mg} \mathrm{dm}^{-3}$ de solo, respectivamente; $\mathrm{Ca}, \mathrm{Mg}, \mathrm{Al},=2,3,0,9$ e $0,6 \mathrm{Cmol}_{\mathrm{c}} \mathrm{dm}^{-3}$ de solo, respectivamente, e teor de matéria orgânica de $2,3 \%$. A textura foi classificada como argilosa.

$\mathrm{O}$ experimento faz parte de um projeto de recomposição florestal, onde as espécies arbóreas nativas foram plantadas em quatro diferentes espaçamentos $(1,0 \times 1,0 ; 1,5 \times 1,5 ; 2,0 \times 2,0$ e $3,0 \times 2,0 \mathrm{~m})$, sendo estes considerados os tratamentos em estudo. As unidades amostrais dos dois primeiros possuem área de $1.700 \mathrm{~m}^{2}$, com 1.700 e 756 covas de plantio, respectivamente e aquelas correspondentes aos espaçamentos $2,0 \times 2,0 \mathrm{e}$ $3,0 \times 2,0 \mathrm{~m}$ apresentam área de $3.300 \mathrm{~m}^{2}$, com 825 e 550 covas, respectivamente.

As mudas foram produzidas no Viveiro Luiz Fernando Oliveira Capellão, pertencente ao Departamento de Silvicultura do Instituto de Florestas da Universidade Federal Rural do Rio de Janeiro e, na época do plantio, apresentavam altura variando de 30 a $90 \mathrm{~cm}$, conforme a espécie.

Inicialmente, a área foi roçada e alguns dias depois foi arada e gradeada e, em seguida, foi marcado o local das covas, obedecendo aos respectivos espaçamentos. Foram abertas covas, manualmente, de $25 \times 25 \times 25 \mathrm{~cm}$, as quais foram adubadas com 100 gramas de N-P-K (0630-06) por cova. Em seguida, executou-se o plantio. A distribuição das mudas no campo obedeceu ao esquema de uma linha de espécie pioneira seguida de outra linha onde foram intercaladas uma muda de espécie pioneira e outra de espécie não pioneira.

O controle das formigas cortadeiras foi realizado dois meses antes do plantio, imediatamente após o plantio e nos doze meses seguintes, com o uso de iscas granuladas.

A primeira capina foi realizada 45 dias após o plantio, em toda área, e as outras até os 17 meses (maio de 2006). O intervalo entre as capinas foi determinado de acordo com observações visuais do crescimento das plantas espontâneas, que, teoricamente, poderiam influenciar de maneira negativa no crescimento das espécies florestais.

Aos 18 meses após plantio, foi realizado levantamento preliminar, por meio de censo, das condições gerais de todas as plantas arbustivas e arbóreas, nos diferentes espaçamentos, quando estas foram classificadas nas seguintes classes de altura: Classe 1: $\leq 2 \mathrm{~m}$; Classe 2: $2 \mathrm{~m}<$ altura $<4 \mathrm{~m}$; Classe $3: \geq 4 \mathrm{~m}$. A partir dessa informação, considerando uma proporção de espécies pioneiras e não pioneiras e a abundância do número de indivíduos de cada espécie nos diferentes 
espaçamentos, foram escolhidas seis espécies para avaliação deste estudo, são elas, Anadenanthera macrocarpa Benth. Brenan (angico vermelho), Schinus terebinthifolius Raddi (aroeira pimenteira), Schizolobium parahyba Blake (guapuruvu), Inga marginata (ingá), Cordia sp. (babosa branca) e Chorisia speciosa St. Hill (paineira). Destas, paineira e ingá são consideradas espécies não pioneiras e as outras quatro pioneiras (CARVALHO, 2003; LORENZI, 1992). Com base nesse levantamento, preliminar, verificou-se que a percentagem de falhas era de $1,5 \%$. Para cada uma dessas espécies foram escolhidas dez plantas (10 repetições) em cada espaçamento (tratamento), levando em consideração a proporção de indivíduos encontrados em cada classe de altura. Após a escolha, essas plantas receberam uma marcação e mediu-se a altura da parte aérea, o diâmetro ao nível do solo (DNS) e a largura da copa (sentidos longitudinal e transversal à linha de plantio), utilizandose, respectivamente, vara graduada, paquímetro e trena. É oportuno ressaltar que nas plantas de guapuruvu não foram realizadas medições de largura da copa, pois na época da avaliação (setembro de 2006), a maioria das plantas dessa espécie não apresentava copa.

Para mensurar a área de copa foram realizadas duas medições da projeção da copa, sendo a primeira no sentido da linha de plantio e a segunda no sentido transversal a esta, conforme adaptações da metodologia utilizada por Fleig et al. (2003). Em seguida, a área de copa foi calculada utilizando a fórmula da elipse, $\mathrm{A}=\mathrm{L} .1 . \pi / 4$, onde: $\mathrm{A}=$ área da copa; $\mathrm{L}=$ comprimento da maior largura da copa; $1=$ comprimento da linha perpendicular à linha de maior largura; $\pi=3,1415$. Para guapuruvu, não foi realizada essa avaliação, pois várias árvores não apresentavam copa no momento da avaliação.

Para cada espécie, o delineamento estatístico utilizado foi o inteiramente casualizado (DIC), constituído por quatro espaçamentos (tratamento). Cada tratamento ou espaçamento de plantio possui dez repetições de cada uma das seis espécies.

Com objetivo de atender às pré-condições de análise de variância, os dados da área de copa de angico, ingá e aroeira e de diâmetro ao nível do solo das duas primeiras espécies, foram transformados em raiz quadrada. Em seguida, realizou-se a análise de variância e, quando houve significância, as médias foram comparadas, pelo teste de Tukey, ao nível de 5\% de significância, utilizandose software SAEG - Sistema de Análises Estatísticas e Genéticas (RIBEIRO JÚNIOR, 2001).

\section{RESULTADOS E DISCUSSÃO}

Constatou-se, para todas variáveis, que as diferentes espécies se comportaram de maneira distinta nos diversos espaçamentos, ao nível de $5 \%$ de probabilidade pelo teste $\mathrm{F}$, não houve diferenças significativas apenas para altura de angico vermelho, de aroeira, de babosa branca e de paineira.

Verifica-se, pela Tabela 1, que, de um modo geral, as espécies apresentaram valores médios de diâmetro ao nível do solo e de área de copa, significativamente superiores nos espaçamentos mais amplos $(2 \times 2$ e 3 x $2 \mathrm{~m}$ ). Segundo Balloni e Simões (1980) e Daniel et al. (1982), normalmente, o espaçamento tem maior influência no crescimento em diâmetro do que em altura. Rondon (2002) observou um aumento do diâmetro das plantas de Schizolobium amazonicum (paricá) com aumento de espaçamento.

A área de copa, assim como no diâmetro ao nível do solo, as plantas de todas as seis espécies avaliadas apresentaram tendência a um maior crescimento nos espaçamentos mais amplos (Tabela 1). Segundo Daniel et al. (1982) e Reis e Reis (1993) a variável está diretamente relacionada com o espaçamento, em razão da maior disponibilidade de recursos ambientais, principalmente luz, para as plantas. Fleig et al. (2003) observaram, em povoamento de erva mate com 14 anos de idade, que o diâmetro da copa foi significativamente influenciado pelo espaçamento nas linhas, com superioridade para os maiores espaçamentos.

Para a variável altura, não se observou um padrão de crescimento claro das diferentes espécies entre os espaçamentos (Tabela 1). Essa ausência de comportamento padronizado pode ser explicada, provavelmente, pela baixa competição intraespecífica, como relatado na literatura (BALLONI; SIMÕES, 1980; DANIEL et al., 1982), pela baixa influência do espaçamento nessa variável, ou pelas características silviculturais de cada uma dessas espécies. Segundo Carvalho (2003), a aroeira pimenteira apresenta crescimento simpodial, ou seja, perde seu ponto vegetativo do eixo principal (gema apical) após a formação de ramificações. Já, o guapuruvu e a paineira apresentam crescimento monopodial (CARVALHO, 2003). Portanto, para essas duas últimas espécies, esperava-se maior crescimento em altura nas plantas dos espaçamentos mais adensados pela maior procura por luz, o que não ocorreu, provavelmente, em razão do efeito das plantas próximas às dessas espécies.

Cerne, Lavras, v. 18, n. 1, p. 159-165, jan./mar. 2012 
Tabela 1 - Valores médios de crescimento de seis espécies florestais em diferentes espaçamentos de plantio, aos 22 meses de idade, na área da SFE - UTE Barbosa Lima Sobrinho, em Seropédica, RJ.

Table 1 - Average growth of six forest species in different planting densities at the age of 22 months, in the SFE - UTE Barbosa Lima Sobrinho, in Seropédica, RJ.

\begin{tabular}{|c|c|c|c|c|}
\hline \multirow{2}{*}{ Característica } & \multicolumn{4}{|c|}{ Espaçamento (m) } \\
\hline & $1,0 \times 1,0$ & $1,5 \times 1,5$ & $2,0 \times 2,0$ & $3,0 \times 2,0$ \\
\hline \multicolumn{5}{|c|}{ Angico Vermelho (Anadenanthera macrocarpa) } \\
\hline Altura (m) & 2,2 a $(1,00)$ & 2,0 a $(0,88)$ & 2,7 a $(1,13)$ & 2,8 a $(0,61)$ \\
\hline DNS $(\mathrm{cm})^{*}$ & $2,08 \mathrm{~b}(1,48)$ & $2,0 \mathrm{~b}(1,11)$ & 4,73 a $(3,39)$ & 5,91 a $(1,93)$ \\
\hline Área de copa $\left(\mathrm{m}^{2}\right)$ & $1,27 \mathrm{c}(1,57)$ & $2,07 \mathrm{bc}(1,51)$ & $4,63 \mathrm{ab}(4,47)$ & 5,77 a $(2,99)$ \\
\hline \multicolumn{5}{|c|}{ Aroeira (Schinus terebinthifolius) } \\
\hline Altura (m) & 2,3 a $(0,58)$ & 2,5 a $(0,33)$ & 2,3 a $(0,43)$ & $2,7 \mathrm{a}(0,52)$ \\
\hline DNS $(\mathrm{cm})^{*}$ & $4,44 \mathrm{c}(1,29)$ & 4,89 bc $(1,97)$ & $6,32 \mathrm{ab}(1,53)$ & 6,94 a $(2,06)$ \\
\hline Área de copa $\left(\mathrm{m}^{2}\right)$ & $1,64 \mathrm{~b}(0,52)$ & 4,57 a $(2,07)$ & 4,49 a $(2,20)$ & $6,40 \mathrm{a}(2,25)$ \\
\hline \multicolumn{5}{|c|}{ Babosa (Cordia sp) } \\
\hline Altura (m) & 4,9 a $(0,94)$ & $4,7 \mathrm{a}(0,64)$ & 4,2 a $(0,84)$ & $4,1 \mathrm{a}(0,67)$ \\
\hline DNS $(\mathrm{cm})^{*}$ & $10,71 \mathrm{~b}(4,14)$ & $13,09 \mathrm{ab}(3,69)$ & $14,63 \mathrm{ab}(4,47)$ & 16,26 a $(4,07)$ \\
\hline Área de copa $\left(\mathrm{m}^{2}\right)$ & $6,47 \mathrm{~b}(3,81)$ & 14,06 a $(6,49)$ & 17,75 a $(6,53)$ & $18,34 \mathrm{a}(6,68)$ \\
\hline \multicolumn{5}{|c|}{ Guapuruvu (Schizolobium parahyba) } \\
\hline Altura (m) & $3,7 \mathrm{~b}(0,74)$ & $4,5 \mathrm{ab}(0,60)$ & 5,2 a $(0,95)$ & 4,1 b $(0,89)$ \\
\hline DNS $(\mathrm{cm})^{*}$ & $6,37 \mathrm{c}(2,19)$ & $10,10 \mathrm{~b}(1,45)$ & $12,76 \mathrm{a}(2,58)$ & $10,22 \mathrm{~b}(1,47)$ \\
\hline \multicolumn{5}{|c|}{ Ingá (Inga marginata) } \\
\hline Altura (m) & $1,9 \mathrm{ab}(0,37)$ & 2,4 a $(0,29)$ & $1,5 \mathrm{~b}(0,70)$ & $1,5 \mathrm{~b}(0,44)$ \\
\hline DNS (cm) & $2,85 \mathrm{~b}(0,68)$ & 5,11 a $(0,83)$ & $3,96 \mathrm{ab}(2,21)$ & $3,89 \mathrm{ab}(0,98)$ \\
\hline Área de copa $\left(\mathrm{m}^{2}\right)$ & $1,31 \mathrm{~b}(0,48)$ & $4,11 \mathrm{a}(1,23)$ & $2,04 \mathrm{~b}(1,53)$ & $2,51 \mathrm{~b}(1,24)$ \\
\hline \multicolumn{5}{|c|}{ Paineira (Chorisia speciosa) } \\
\hline Altura (m) & 3,4 a $(0,89)$ & 2,8 a $(0,84)$ & 3,3 a $(0,79)$ & 3,2 a $(0,53)$ \\
\hline DNS $(\mathrm{cm})^{*}$ & $8,03 \mathrm{~b}(3,32)$ & $8,06 \mathrm{~b}(3,48)$ & 12,94 a $(3,15)$ & 11,81 a $(2,05)$ \\
\hline Área de copa $\left(\mathrm{m}^{2}\right)$ & $2,51 \mathrm{~b}(2,30)$ & $2,92 \mathrm{~b}(1,38)$ & 7,33 a $(3,41)$ & 7,17 a $(2,59)$ \\
\hline
\end{tabular}

*Diâmetro ao nível do solo.

Médias seguidas pela mesma letra, na linha, não diferem entre si pelo teste de Tukey $(\mathrm{P}<0,05)$.

Números entre parênteses refere-se ao desvio padrão.

Embora os valores médios de crescimento em altura nos diferentes espaçamentos para a babosa não tenham apresentado diferença significativa pode-se notar que eles foram aumentando conforme a densidade de plantas, já, os valores médios de área de copa e DNS apresentaram comportamento contrário, sendo maiores nos espaçamentos mais amplos. Essa foi a espécie que melhor demonstrou o comportamento de estiolamento esperado nos espaçamentos mais adensados.

Cerne, Lavras, v. 18, n. 1, p. 159-165, jan./mar. 2012

Cerme, Lavras,
Para as plantas de ingá, os maiores valores médios em todas as variáveis foram observados no espaçamento $1,5 \times 1,5 \mathrm{~m}$, já os menores valores de DNS e copa foram observados no $1,0 \times 1,0 \mathrm{~m}$ e de altura nos espaçamentos $2,0 \times 2,0$ e $3,0 \times 2,0 \mathrm{~m}$, ambos com o mesmo valor. $\mathrm{O}$ maior crescimento do ingá no espaçamento $1,5 \times 1,5 \mathrm{~m}$ sugere, que até certo nível, é benéfica para essa espécie a competição causada pelo adensamento no plantio. Provavelmente, pelo fato desta ser uma espécie secundária 
(LORENZI, 1992) que tem preferência por ambientes com certo grau de sombreamento.

As plantas de guapuruvu apresentaram maiores valores médios no espaçamento 2,0 × 2,0 m, e menores no $1,0 \times 1,0 \mathrm{~m}$. O maior crescimento em altura e menor em diâmetro verificados no espaçamento $1,5 \times 1,5 \mathrm{~m}$ em relação ao $3,0 \times 2,0 \mathrm{~m}$, denotam uma tendência de estiolamento da espécie. No 1,0 × 1,0 m a competição foi intensa demais sendo observado um grande número de plantas dominadas.

Toledo Filho e Parente (1982), verificando o crescimento de espécies nativas do estado de São Paulo sob a sombra de povoamentos de Pinus, aos 8 anos de idade, concluíram que espécies pioneiras como Enterolobium contortisiliquum (tamboril) e Machaerium nictitans (bico de pato) com, respectivamente, 4,39 e 3,67 $\mathrm{m}$ de altura e 5,7 e 2,8 cm de DAP, apresentam crescimento inferior a uma espécie de mesmo estágio sucessional do atual trabalho. Os valores médios encontrados neste trabalho, para as plantas de Schizolobium parahyba no espaçamento 2,0 x 2,0 m, foram de 5,2 $\mathrm{m}$ de altura e $12,7 \mathrm{~cm}$ de diâmetro ao nível do solo. Essa superioridade pode ser explicada pelas diferentes condições edafoclimáticas entre os locais, pelas características silviculturais da espécie e pela distribuição espacial das espécies no campo.

Para angico vermelho, aroeira e paineira foi observado em geral o mesmo comportamento, em que, para diâmetro e área de copa, os maiores valores médios foram encontrados nos espaçamentos de plantio menos adensados. Isso indica que, diferente do ingá e do guapuruvu, essas espécies têm preferência por espaçamentos mais abertos e não aparentam se beneficiar da competição.

Fonseca et al. (1990) observaram que os espaçamentos de plantio $(2 \times 2,3 \times 2,4 \times 2$ e $3 \times 3 \mathrm{~m})$ não influenciaram o crescimento médio de altura de Dalbergia nigra, aos 5 anos após o plantio, provavelmente, segundo os autores, em virtude da baixa competição entre os indivíduos nesta idade.

Em trabalho de recomposição florestal, com várias espécies florestais plantadas no espaçamento de 1,0 x 1,0 $\mathrm{m}$, em área do entorno do Parque Nacional do Desengano, Região Serrana do Rio de Janeiro, Piña-Rodrigues et al. (1997a) observaram que, aos 14 meses após o plantio, Schizolobium parahyba, Anadenanthera macrocarpa, Schinus terebinthifolius e Chorisia speciosa apresentaram altura média, respectivamente, de 2,4;2,2; 1,9 e 1,3 m e correspondente diâmetro ao nível do colo de 4,70; 2,31;
1,82 e $3,04 \mathrm{~cm}$. Os valores encontrados para angico e aroeira no presente trabalho (Tabela 1) são semelhantes, embora a medição de Piña-Rodrigues et al. (1997a) tenha sido feita com o povoamento em idade mais precoce, o que pode ser explicado em decorrência das diferenças edafoclimáticas locais, a qualidade das mudas e os tratos silviculturais aplicados. Já, os valores encontrados para guapuruvu e paineira como é de se esperar, são menores que os do presente trabalho. Esse trabalho de Piña-Rodrigues et al. (1997a) mostra, também, que as espécies que mais se destacaram em ordem decrescente de crescimento, até os 14 meses após o plantio, foram Plathymenia foliolosa, Senna multijuga, Inga edulis, Parapiptadenia gonoacantha, Schizolobium parahyba e Anadenanthera macrocarpa.

Barbosa et al. (1997) testaram, no entorno de uma várzea do Município de Santa Cruz das Palmeiras, SP, 14 modelos de repovoamento florestal heterogêneo, implantados em três espaçamentos $(2,5 \times 2,5 ; 2,0$ x 4,0 e 4,0 x 4,0 m) e pela distribuição espacial de oito espécies florestais pioneiras, e observaram que Schizolobium parahyba, plantado no espaçamento $2,5 \mathrm{x}$ 2,5 m, apresentou valores de altura total, circunferência à altura do peito (CAP) e projeção de copa, aos 16 meses após plantio, significativamente superiores aos demais espaçamentos. Os valores de crescimento de guapuruvu variaram de 3,7 a $4,0 \mathrm{~m}$ de altura, dependendo da distribuição das espécies, e são bem próximos à média das plantas do espaçamento $3 \times 2 \mathrm{~m}$ deste trabalho, que foi de 4,1 m, aos 22 meses de idade (Tabela 1). Já, Schinus terebinthifolius foi plantada apenas nos espaçamentos $2 \mathrm{x}$ 4 e $4 \times 4 \mathrm{~m}$, e os autores constataram que as plantas não apresentaram diferenças significativas no crescimento, aos 16 meses de idade.

Durigan e Silveira (1999), em experimento visando à recuperação da cobertura florestal da mata ciliar em domínio de cerrado, em Assis - SP, observaram que o angico do cerrado (Anadenanthera falcata), aos 18 meses após plantio, no espaçamento $3,0 \times 1,5 \mathrm{~m}$, apresentou menor altura e diâmetro ao nível do solo (DNS) do que o angico vermelho (Anadenanthera macrocarpa), utilizado no atual trabalho. As plantas dessa espécie, no espaçamento $3,0 \times 2,0 \mathrm{~m}$, aos 22 meses após plantio, apresentaram valores médios de altura de $2,8 \mathrm{~m}$ e de DNS igual a $5,9 \mathrm{~cm}$. Tal superioridade pode ser evidenciada pela diferença de idade dos plantios, pelo maior espaço disponível entre as plantas e pelas diferentes características edafoclimáticas locais.

Cerne, Lavras, v. 18, n. 1, p. 159-165, jan./mar. 2012 
Oliveira et al. (2005), estudando restauração florestal na região de Porecatu, PR, avaliaram o efeito do espaçamento de plantio $(3,0 \times 2,0 ; 3,0 \times 1,5 ; 2,0 \times 1,5$ e 3,0 x 1,0 m), no crescimento, em altura e diâmetro de colo de 15 espécies florestais nativas, sendo três pioneiras, seis secundárias iniciais, quatro secundárias tardias e duas climácicas, em diferentes modelos de arranjo das espécies, aos 6 e 12 meses após o plantio. Esses autores constataram que, nas duas idades de avaliação, as plantas do espaçamento 2,0 × 1,5 m foram as que apresentaram maior crescimento e as plantas de menor crescimento foram aquelas do espaçamento 3,0 x 1,0 m, evidenciando que não apenas a área disponível é importante quando se trata de espaçamento, mas também a disposição das plantas, que permite o melhor uso dos recursos ambientais, principalmente luz (REIS; REIS, 1993).

\section{CONCLUSÕES}

O espaçamento de plantio teve influência significativa, aos 22 meses, no crescimento em diâmetro ao nível do solo e na área de copa de todas as espécies. Em geral, nos espaçamentos mais amplos, observou-se maior crescimento.

\section{AGRADECIMENTOS}

À Usina Termoelétrica Barbosa Lima Sobrinho, por disponibilizar a área e os recursos que tornaram possível a realização do trabalho.

\section{REFERÊNCIAS}

BALLONI, E. A.; SIMÕES, J. W. O espaçamento de plantio e suas implicações silviculturais. IPEF, Piracicaba, v. 1, n. 3, p. $1-16,1980$.

BARBOSA, L. M.; SANTOS, M. R. O.; LOTTI, D. M.; ASPERTI, L. M. Comportamento inicial de espécies arbóreas nativas em comunidades implantadas e seu potencial de utilização. In: SIMPÓSIO NACIONAL DE RECUPERAÇÃO DE ÁREAS DEGRADADAS, 3., 1997, Ouro Preto. Anais... Ouro Preto: SOBRADE/UFV, 1997. p. 384-402.

BOTELHO, S. A. Espaçamento. In: SCOLFORO, J. R. S. (Ed.). Manejo florestal. Lavras: UFLA/FAEPE, 1998. p. 381-406.

BRASIL. Lei no 11.428, de 26 de dezembro de 2006. Brasília, 2006. Disponível em: <http://www. sbs.org.br>. Acesso em: 27 dez. 2006.

Cerne, Lavras, v. 18, n. 1, p. 159-165, jan./mar. 2012
BRASIL. Ministério de Minas e Energia. Projeto RADAM Brasil. Rio de Janeiro, 1980. 460 p.

CARVALHO, P. E. R. Espécies arbóreas brasileiras. Colombo: Embrapa Florestas, 2003. 1039 p.

DANIEL, T. W.; HELMS, J. A.; BACKER, F. S. Princípios de silvicultura. México: McGraw-Hill, 1982. 492 p.

DURIGAN, G.; SILVEIRA, E. R. Recomposição da mata ciliar em domínio de cerrado, Assis, SP. Scientia Forestalis, Piracicaba, n. 56, p. 135-144, 1999.

FLEIG, F. D.; SCHNEIDER, P. R.; FINGER, C. A. G. Influência do espaçamento e idade da brotação na morfometria de povoamentos de Illex paraguariensis St. Hill. Ciência Florestal, Santa Maria, v. 13, n. 1, p. 73-88, 2003.

FONSECA, C. E. L.; BUENO, D. M.; SPERÂNDIO, J. P. Comportamento do Jacarandá-da-baía aos cinco anos de idade, em quatro diferentes espaçamentos em Manaus, AM. Revista Árvore, Viçosa, v. 14, n. 2, p. 78-84, 1990.

LORENZI, H. Árvores brasileiras: manual de identificação e cultivo de plantas arbóreas nativas do Brasil. Nova Odessa: Plantarum, 1992. 352 p.

NOGUEIRA, J. C. B.; SIQUEIRA, A. C. M. S. Plantio de coração de negro (Poecilanthe parviflora) em diferentes espaçamentos. Silvicultura em São Paulo, São Paulo, v. 11/12, p. 93-96, 1977.

OLIVEIRA, R. E.; GUSSON, E.; TOYAMA, I. T.; CANOVAS, R. F.; GANDARA, F. B.; KAGEYAMA, P. Y. Níveis de refinamento de uso dos grupos ecológicos e densidade de plantio para restauração florestal com espécies arbóreas nativas. In: SIMPÓSIO NACIONAL E CONGRESSO, 6.; CONGRESSO LATINO AMERICANO DE ÁREAS DEGRADADAS, 1., 2005, Curitiba. Anais... Curitiba: UFPR, 2005. p. 562-563.

PIÑA-RODRIGUES, F. C. M.; LOPES, L. R.; BLOOMFIELD, V. K. Análise do desenvolvimento de espécies arbóreas da Mata Atlântica em sistema de plantio adensado para revegetação de áreas degradadas em encostas, no entorno do Parque Estadual do Desengano, RJ. In: SIMPÓSIO NACIONAL DE RECUPERAÇÃO DE ÁREAS DEGRADADAS, 3., 1997, Ouro Preto. Anais... Ouro Preto: SOBRADE/UFV, 1997a. p. 283-291. 
PIÑA-RODRIGUES, F. C. M.; LOPES, L. R.; MARQUES, S. Sistema de plantio adensado para revegetação de áreas degradadas da Mata Atlântica: bases ecológicas e comparações de estudo: benefício com o sistema tradicional. Floresta e Ambiente, Seropédica, ano 4, p. 30-41, 1997b.

REIS, G. G.; REIS, M. G. F. Competição por luz, água e nutrientes em povoamentos florestais. In: SIMPÓSIO BRASILEIRO DE PESQUISA FLORESTAL, 1., 1993, Belo Horizonte. Anais... Viçosa, MG: SIF/UFV, 1993. p. 161173.

RIBEIRO JÚNIOR, J. I. Análises estatísticas no SAEG. Viçosa, MG: UFV, 2001. 301 p.
RONDON, E. V. Produção de biomassa e crescimento de árvores de Schizolobium amazonicum (Hub.) Ducke sob diferentes espaçamentos na região de mata. Revista Árvore, Viçosa, v. 26, n. 5, p. 573-576, set./out. 2002.

SOUZA, C. C. Modelo de crescimento, com variáveis ambientais, para o ipê felpudo em diferentes espaçamentos. 2004. 96 p. Dissertação (Mestrado em Recursos Florestais) - Escola Superior de Agricultura "Luiz de Queiroz”, Piracicaba, 2004.

TOLEDO FILHO, D. V.; PARENTE, P. R. Essências indígenas sombreadas. Silvicultura em São Paulo, São Paulo, v. 16A, n. 2, p. 948-58, 1982.

Cerne, Lavras, v. 18, n. 1, p. 159-165, jan./mar. 2012 